cat came to an untimely end eighteen months ago, but the only surviving kitten of the five named above is as fond of the dog as her mother was. She brings mice, young rats, and rabbits, and lays them down before "Cato," and looks beseechingly till he takes them. She constantly plays with him and gets on her hind legs to look fondly into his face, while he puts his paws round her as he used to do to her mother.

She must have inheriled this affection from her mother, as she was too young to have imitated her mother's actions at the time of her death.

Clent, July I3

\section{Scarcity of Birds}

I SHOULD much like to know whether blackbirds and thrushes are scarce in other localities this year; because they have most unaccountably vanished from this neighbourhood, with the excep. tion of a very few stragglers. Our cherries and strawberries are untouched. I have not observed a single blackbird or thrush in our garden or pleasure-grounds since the fruit ripened, though every olher year we captured several in the cherry-nets, and shot many others.

Fassaroe Dray, co. Wicklow, July I2

\begin{abstract}
R. M. BARRINGTON
\end{abstract}
\section{OUR ASTRONOMICAL COLUMN}

VARIABLE STARS.- Of the three stars to which Col. Tennant draws attention as being probably variable ("Monthly Notices R.A.S." June r875), B.A.C. 740 appears more especially deserving of regular observation. The B.A.C. has adopted the magnitude assigned by Groombridge, 6; other estimates are :-Hevelius, 6 ; Fedorenko (Lalande, 1789 November), 8 ; Piazzi, 8, by

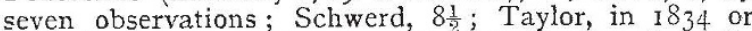
1835, in vol. iii. of "Madras Observations," 7 (he calls the star 2I Cephei); Carrington, 8.1; the Radcliffe Catalogues, 7.5 ; and Durchmusterung, 8.4 . With regard to the observation of Hevelius, which has been assumed to refer to this star, it may be remarked that the position given in his Catalogue for 1660 , where it is No. 46 in Cepheus, does not well agree with the place of the Redhill Catalogue for B.A.C. 740, the difference of position amounting to $16^{\prime}$; nevertheless it is not easy to identify the star observed by Hevelius with any other in the modern catalogues. In the cases of the stars B.A.C. 4166 and 4193 , also noticed by Col. Tennant, the estimates of magnitude from the epoch of Schwerd's observations to the present time appear pretty accordant. In comparing the magnitudes assigned in different catalogues to the naked-eye stars it is necessary to bear in mind that in Argelander's Uranometria, and in Heis and Behrmann, 6.5, 5.4, \&c., apply to stars which are judged to be somewhat brighter than an average sixth or fifth magnitude, and are not to be understood decimally, as is the case in the "Durchmusterung."]

TrE DOUBLE-STAR $\Sigma$ 1785.--The proper motion of this star is investigated in Argelander's researches, Bonn Observations, vol. 7. He remarks : "Die Begleiter geht mit," and of this there can be no doubt, since in the interval between Struve's first measures and the last published by the Baron Dembowski, the amount of proper motion, according to Argelander's values, would be $-20^{\prime \prime} \cdot 9$ in R.A. and $-2^{\prime \prime} \cdot 4$ in Decl. Dut the relative fixity of the components, which might have been surmised from Argelander's comparison of his differences of R.A. and Decl. for $1867^{\circ} 34$, with those decluced from Struve's angle and clistance in 1830 , is clearly refuted by the recent measures. Thus we have-

Struve $\ldots . \ldots \quad 1830^{\circ} 12$ Position $164^{\circ} \cdot 43$ Distance $3^{\prime \prime} 487$

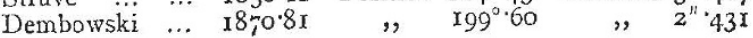

Perhaps it is not yet practicable to decide whether this relative change is due to slight difference of proper motion o: to the binary character of the star, but it is evidently one that should be regularly measured. The position for the beginning of the present year is R.A. $13 \mathrm{~h}, 43 \mathrm{~m} .24 \mathrm{~s}$, and N.P.D. $62^{\circ} 23^{\prime \prime} 6$

The Total Solar Eclipse, 1927, June 29.-We believe the Rev. S. J. Johnson, of Upton Helions, Devon, was the first who pointed out the probable totality of this eclipse for a short interval in this country. It is one of those eclipses in which the moon's augmented semidiameter exceeds that of the sun by a small quantity, even where the sun is on the meridian. The following are approximate elements :-

Conjunction in R. A. 1927 , June 28 , at $18 \mathrm{~h}, 27 \mathrm{~m}$. I4S. G. M.T.

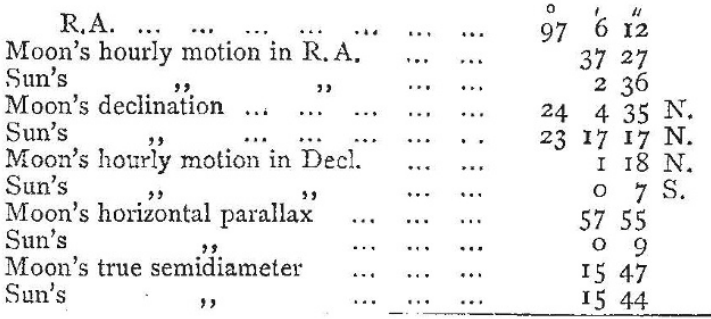

The sidereal time at Greenwich noon on June 29 is $6 \mathrm{~h} .26 \mathrm{~m}$. I7s., and the equation of time $3 \mathrm{~m}$. 35 . subtractive from mean time. The middle of general eclipse at 18h. $23 \mathrm{~m}$. I7s.

Hence the following points on the central line :-

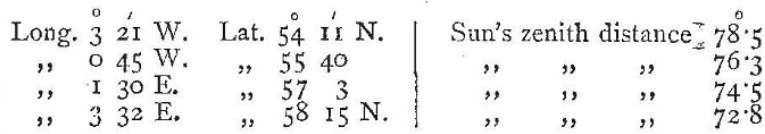

In $1^{\circ} 37^{\prime} \mathrm{W}$. and $55^{\circ} \mathrm{I} 2^{\prime} \mathrm{N}$. totality begins according to the above elements, June 28 at $17 \mathrm{~h}$. $19 \mathrm{~m}$. 3Is. local mean time, and continues only nine seconds. It will be seen that the track of the central line in its passage over England is from Windermere, a little north of Morpeth, to the Northumberland Coast ; it appears to just escape the Isle of Anglesey, but our data are not quite definitive.

MINOR PlanETS,-M. Stéphan has calculated elements of No. I46, discovered by M. Borrelly, from the Marseilles observations of June 9, I8, and 29, which give as a first approximation to the period of revolution, 1627 days; the planet has been named Lucina. Euphrosyne is in opposition about this time, with $57^{\circ}$ South Declination; this body makes one of the widest excursions of any in the group, and may at times be found in Ursa Major. Daphne is the brightest of the small planets now near opposition.

\section{SCIENCE IN GERMANY \\ (From a German Correspondent.)}

$\mathrm{IN}$ continuation of the last report (p. I52) we make the following further communication on Götte's "History of Development." As we have already mentioned, Götte deduces the structure of the embryo from the difference in size and position of the parts resulting from the division of the ovum. He supports this theory by the following observations. In the case of all ova, first of all a difference shows itself in the vertical axis, the parts round the upper pole being smaller and generating quicker than those round the under pole. The ratio of displacement is therefore also much greater in the upper hemisphere; and as this one expands concentrically it overgrows downwards the more bulky lower hemisphere, or causes it to bulge inwards, so that from the ovum which divides into many cell-like pieces, results a beaker-shaped 